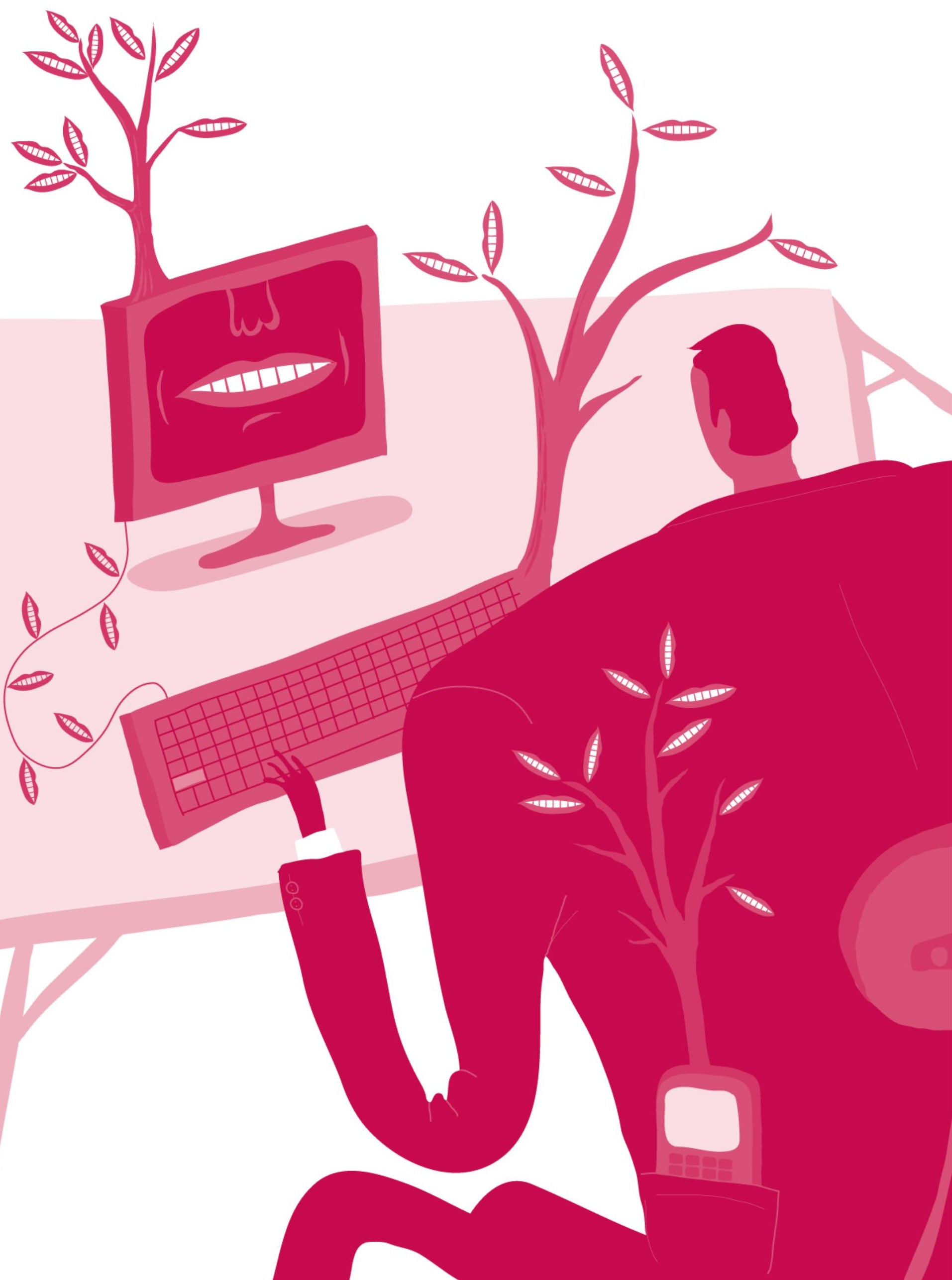




\section{Política de Comunicação e gestão empresarial: a experiência da Embrapa}

Jorge A. M. Duarte

- Doutor em Comunicação Social pela Universidade Metodista de São Paulo

- Graduado em Jornalismo e em Relações Públicas

- Técnico da área de Comunicação Social da Empresa Brasileira de Pesquisa Agropecuária (Embrapa)

- Atua na Secretaria de Comunicação Social (Secom) da Presidência da República

- Coordenador nacional da Reunião Especializada em Comunicação Social (RECS) do Mercosul

- Membro da equipe consultiva da Cátedra Unesco/Metodista de Comunicação para o Desenvolvimento Regional

- Membro do Conselho Consultivo da Sociedade Brasileira de Estudos Interdisciplinares de Comunicação (Intercom)

- Membro do Conselho Editorial da Organicom

- jorge.duarte@planalto.gov.br

Heloiza Dias da Silva

- Doutoranda e mestre em Comunicação Social pela Universidade Metodista de São Paulo

- Especialista em Divulgação Científica e Tecnológica pela Universidade de Brasília (UnB)

- Graduada em Jornalismo pelo Centro Universitário de Brasília (UniCeub)

- Desde 1978, é funcionária da Embrapa, onde exerceu diversas funções nas áreas de informação e documentação, difusão de tecnologia e assessoria de imprensa

- Foi chefe da Assessoria de Comunicação Social da Embrapa de 1996 a 2003, tendo coordenado a elaboração e a implementação da Política de Comunicação da empresa

-heloizadias@brturbo.com.br 
O texto sintetiza a experiência da Empresa Brasileira de Pesquisa Agropecuária (Embrapa) na construção de sua Política de Comunicação, destinada a ajudar a organização a qualificar sua ação no novo ambiente social aberto com a redemocratização, na década de 1980. Apresentam-se também exemplos dos mecanismos utilizados pela empresa para inserir estrategicamente a comunicação em sua Política Geral de Administração e incorporá-la em todas as instâncias da organização.

PALAVRAS-CHAVE: COMUNICAÇÃO ORGANIZACIONAL • GESTÃo • POLÍtICA dE COMUNICAÇÃO

\section{Abstract}

The text summarizes the experience of Empresa Brasileira de Pesquisa Agropecuária (Embrapa, or Brazilian Agriculture and Animal Breeding Research Corporation) in the construction of its Communication Policy, aimed at helping the organization to qualify its actions in the new open social environment that resulted from redemocratization in the 1980 s decade. Also presented are examples of the mechanisms used by the company to strategically insert communication in its General Management Policy and blend it into all of the organization's levels.

KEYWORDS: ORGANIZATION COMMUNICATION • MANAGEMENT • COMMUNICATION POLICY

\section{Resumen}

Se sintetiza la experiencia de la Empresa Brasileira de Pesquisa Agropecuária (Embrapa) para elaborar su Política de Comunicación, cuyo objetivo es ayudar a la firma a calificar sus prácticas en el nuevo ambiente social que surgió con la redemocratización, en la década de 1980. También se presentan ejemplos de los mecanismos utilizados por Embrapa para incluir la comunicación estratégicamente en su Política General de Administración e incorporarla a todas las instancias de la empresa.

PALABRAS CLAVE: COMUNICACIÓN ORGANIZACIONAL - GESTIÓN - POLÍTICA de COMUNICACIÓN 
$\mathrm{E}$ m revisão bibliográfica sobre os conceitos em Comunicação Organizacional, Kunsch (2003, p. 69-88) destaca a concordância entre diferentes autores sobre a estreita relação entre organização e comunicação. Cita, por exemplo, Thayer, para quem qualquer sistema organizacional se viabiliza graças ao sistema de comunicação nele existente. Segundo ele, "é a comunicação que ocorre dentro dela (a organização) e a comunicação entre ela e seu meio ambiente que a definem e determinam as condições de sua existência e a direção de seu movimento" (THAYER, 1976, p. 120). Kunsch lembra ainda Katz e Kahn (1987, p. 35), para quem "as organizações sociais precisam também de suprimentos renovados de energia de outras instituições, de pessoas, ou do meio ambiente material. Nenhuma estrutura social é auto-suficiente ou autocontida", ou seja, de acordo com Kunsch (2003, p. 70), "a interdependência das organizações em si as leva ao relacionamento e à integração com as demais e de cada uma em si com seu mundo interno e externo. E isto só se dará por meio da comunicação e na comunicação".

A comunicação, nessa perspectiva, é como energia vital, um fluxo, um instrumento para potencializar o sucesso organizacional, afetando diretamente a rotina e os resultados organizacionais. Mas a Comunicação Organizacional somente tem a chance de ser utilizada estrategicamente em toda sua plenitude em um ambiente democrático, participativo, em que a pluralidade se viabilize, exigindo que a organização informe, dê acesso, explique, oriente e se veja com a necessidade de estabelecer vínculos fortes e transparentes com seus públicos de interesse. Por isso, o processo de redemocratização da década de 1980 foi o ponto de partida para uma nova etapa na comunicação das organizações brasileiras. Finda a clausura estabelecida pelo regime militar, estabelece-se um outro estágio na relação entre organizações e seus diferentes públicos. Essa nova fase é decorrente de fatores como maior competitividade no mercado, reforma administrativa no serviço público, conquistas no âmbito da cidadania, a importância cada vez maior da opinião pública e o irrefreável aumento do nível de exigência dos consumidores.

Uma das conseqüências mais importantes é que a interação entre organizações e sociedade ficou mais complexa. A percepção das organizações sobre o ambiente em que estão inseridas - e também da sociedade sobre a identidade das organizações - se torna diferencial competitivo relevante e a comunicação assume papel fundamental e estratégico para as organizações. Saíram de cena os comunicadores que agiam "cada um por si” ou cuja função era comandar núcleos isolados. As organizações passaram a ter necessidade de praticar comunicação integrada e estratégica, e não mais asses- 
soria de imprensa, eventos, publicações, Internet, por exemplo, como áreas isoladas e operacionais.

Integrar a comunicação, tornando-a coesa, uniforme, coerente, em suas diferentes formas de processamento, com os objetivos e metas das organizações, passou a ser um desafio. Os modelos de gestão empresarial voltaram-se para a relação com clientes, fornecedores, acionistas, empregados e com a comunidade, levando as organizações a um reposicionamento da comunicação, menos operacional e mais estratégica, integrada ao processo de tomada de decisões. Como um instrumento de inteligência competitiva, a comunicação passou a requerer planejamento mais qualificado, capacitação e práticas avançadas de coleta, tratamento, recuperação e transmissão das informações (BUENO, 2003).

Pela consciência cada vez maior desse papel, nas duas últimas décadas a qualificação da comunicação ganhou velocidade e status, transformando-se num campo de trabalho profícuo e atraindo profissionais de todas as áreas, ávidos por suas oportunidades e possibilidades. Segundo Bueno (2003, p. 8), essa nova área que surge rompendo as fronteiras tradicionais que a identificavam nas décadas anteriores deixa de ser mero apêndice do processo de gestão e incorpora "uma série de atributos que a tipificam como insumo estratégico".

Entre os requisitos que se estabeleceram para a efetividade da Comunicação Organizacional, passaram a ser decisivos a profissionalização, o planejamento permanente das atividades, avaliação sistemática, flexibilidade, visão global e sistêmica, segmentação, capacidade crítica e compreensão e atendimento das necessidades de cada público de interesse.

A Empresa Brasileira de Pesquisa Agropecuária (Embrapa), órgão vinculado ao Ministério da Agricultura, Pecuária e Abastecimento, como instituição líder na geração de conhecimentos e tecnologias para o agronegócio do mundo tropical, não ficou passiva frente às mudanças que se vislumbravam. Na década de 1990, investiu fortemente num programa de reestruturação para reduzir sua dependência de recursos públicos, modernizar a administração e torná-la mais presente no mercado, inclusive por meio de parcerias com a iniciativa privada. Para isso, incorporou conceitos administrativos como planejamento estratégico, gestão pela qualidade total, aplicação de enfoque sistêmico na gestão e pesquisa orientada para o mercado. Adotou também os conceitos de comunicação integrada e planejada, além de utilizá-la como instrumento de qualificação dos processos gerenciais e de informação e relacionamento com públicos de interesse.

Este trabalho tem por objetivo relatar o processo de construção e implantação da Política de Comunicação da Embrapa, com base no qual a comunicação assumiu posição estratégica no novo modelo de gestão da empresa, ao lado das áreas de pesquisa e de transferência de tecnologia. 
POLÍTICA DE COMUNICAÇÃO E GESTÃO EMPRESARIAL: A EXPERIÊNCIA DA EMBRAPA JORGE DUARTE E HELOIZA DIAS DA SILVA

\section{A construção da Política de Comunicação da Embrapa}

A Embrapa atua por intermédio de 38 centros de pesquisa, três serviços e 11 unidades centrais, estando presente em quase todos os Estados da Federação, nas mais diferentes condições ecológicas. Para chegar a ser uma das maiores instituições de pesquisa do mundo tropical, a empresa investiu, sobretudo, no treinamento de recursos humanos, tendo, hoje, 8.619 empregados, dos quais 2.221 são pesquisadores, $45 \%$ com mestrado e 53\% com doutorado, operando um orçamento acima de R\$ 1 bilhão em 2007.

As primeiras ações de comunicação da Embrapa datam de 1973, ano de sua criação. $\mathrm{Na}$ época, não havia estrutura formalizada e o trabalho nessa área era desenvolvido em torno da divulgação de informações por um assessor de imprensa vinculado ao gabinete do presidente da empresa. A primeira equipe de comunicação começou a ser montada em 1977, com a contratação de um jornalista e de uma relações-públicas (DUARTE, 1996).

Nos primeiros anos de existência da Embrapa, a comunicação era basicamente uma ferramenta para transferência de tecnologia. E as atividades de comunicação muitas vezes eram coordenadas por profissionais de agronomia ou veterinária, desarticuladas institucionalmente e voltadas basicamente para comunicação com produtores rurais. Uma série de fatores estabelecidos a partir da década de 1990 fez com que a comunicação fosse gradativamente se estruturando. Talvez seja possível estabelecer dois marcos originais nesse processo. O primeiro deles foi a contratação de profissionais por meio de concurso público. O segundo, a definição de uma Política de Comunicação que institucionalizou, fortaleceu e deu as bases para a qualificação permanente da comunicação.

Os profissionais de comunicação - a maior parte, jornalistas - começaram a ser contratados nos centros de pesquisa da Embrapa no início da década de 1980 como técnicos especializados em Comunicação Social, em geral alocados no setor de Difusão de Tecnologia, área responsável pela articulação externa da organização e que concentrava as atividades de comunicação, voltadas prioritariamente para o setor agropecuário. Sua chefia, em geral, era de um gerente intermediário. Faltava, até aquele

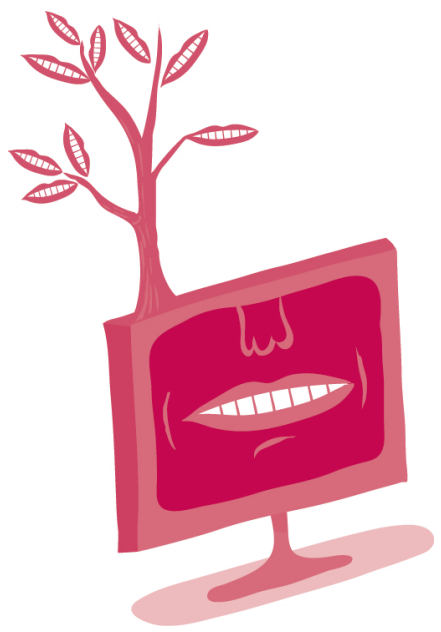


POLÍTICA DE COMUNICAÇÃO E GESTÃO EMPRESARIAL: A EXPERIÊNCIA DA EMBRAPA • JORGE DUARTE E HELOIZA DIAS DA SILVA

momento, a compreensão e a conseqüente valorização de sua atividade. A comunicação era instrumento de mão única, para simples divulgação, e havia pouca interação com públicos de interesse - exceto produtores rurais.

Não houve reconhecimento do comunicador como um técnico especializado e havia desconhecimento sobre seu papel e suas possibilidades de atuação. Os comunicadores eram como o elo final da corrente, atuando no papel de divulgar o que lhes era informado e de exercer funções operacionais. Naquele período de comunicação fragmentada, a desarticulação dos comunicadores dos centros de pesquisa com os da sede afetava a forma como a empresa se apresentava perante a sociedade, impedindo a troca de informações e de experiências e inviabilizando a comunicação integrada na organização. ${ }^{1}$

Esforços foram empreendidos em diferentes momentos pelos profissionais da área para mudar o quadro de baixa priorização da comunicação na Embrapa. Em 1982, por exemplo, surgiram iniciativas isoladas voltadas à definição de diretrizes e à normatização de ações de comunicação que geraram importantes documentos, mas as propostas não foram efetivadas. Em 1990, houve a primeira tentativa de elaboração de uma Política de Comunicação, que acabou se limitando a um documento orientador.

A questão, entretanto, continuou sendo tema freqüente de discussões entre os profissionais da área que, por falta de diretrizes para a comunicação, atuavam de forma desarticulada. Apenas uma vez ocorrera uma reunião entre profissionais desde a fundação da Embrapa; e num período sem Internet, com ligações interurbanas rigidamente controladas, os contatos eram mais comuns em feiras e exposições.

Como conseqüência da dispersão, os centros de pesquisa da empresa adotaram posturas independentes em termos de comunicação, atuando de forma isolada e descoordenada, fazendo com a que a Embrapa fosse vista pelos públicos de maneira fragmentada, enfraquecendo a sua imagem e comprometendo a integridade de sua identidade. A própria logomarca da empresa era utilizada, nas peças de comunicação e em publicações técnicas, sem qualquer padrão visual, à mercê de diferentes tamanhos, formatos e cores.

\section{Da fragmentação à visão integrativa}

Mais visíveis desde o final dos anos 1980, as novas exigências do ambiente externo ganharam força nos primeiros anos da década de 1990, passando a demandar da empresa uma postura mais transparente, ágil e orientada para o mercado, o que reforçou ainda mais a necessidade de se estabelecer um sistema de comunicação organizado e diretrizes gerais para a área.

1 Ver mais sobre o assunto detalhadamente em Duarte (1996) e resumidamente em Duarte (2006). 
Mais do que gerar informações, tecnologias e serviços, a empresa deveria atrair e conquistar a estima e a boa vontade de seus públicos. Era preciso atuar tanto na busca de qualidade e rapidez nas soluções para as necessidades da sociedade quanto no fortalecimento de sua reputação e reconhecimento institucional. Ciente disso, a diretoria da Embrapa priorizou, em 1995, o desenvolvimento de um amplo programa de comunicação da empresa com os seus públicos, orientado por uma Política de Comunicação Empresarial, a qual - juntamente com as Políticas de P\&D (Pesquisa e Desenvolvimento) e de Transferência de Tecnologia - daria, a partir de então, sustentação à Política de Administração da instituição.

Elaborada com base em um diagnóstico organizacional, a Política de Comunicação da Embrapa teve origem no engajamento de dirigentes, no comprometimento dos profissionais, nos objetivos estratégicos da empresa, na experiência prática de quem atuava com comunicação no período, na cultura (bastante específica de uma instituição de pesquisa) e também nas teorias de Comunicação Organizacional e Integrada.

O processo de construção da Política envolveu um grupo central integrado por representantes das diferentes áreas que atuavam com comunicação, um subgrupo de chamados "especialistas" da empresa, inclusive representando unidades e diferentes áreas, e também um consultor, Wilson da Costa Bueno. Contou, principalmente, com a participação, ao longo de cerca de um ano, de todos os envolvidos com a comunicação da empresa, nas mais diferentes áreas. As reuniões com dirigentes e as do próprio grupo central geraram a estrutura central do documento. As reuniões regionais com todos os agentes de comunicação geraram debates e subsidiaram o conteúdo até a aprovação, pela diretoria da empresa, do texto final ${ }^{2}$.

Como estratégia principal para internalizar a Política, foram realizados seminários regionais, que reuniram 254 profissionais ligados direta ou indiretamente à comunicação, além de gerentes da empresa. Esses seminários, aliados à realização de uma ampla campanha interna - que apresentou a comunicação como um compromisso de todos os empregados, e não somente de um departamento ou área -, foram decisivos para que a comunicação começasse a ser compreendida como processo estratégico, numa empresa que, até então, basicamente, restringia sua atuação de comunicação ao apoio à difusão de tecnologias.

Uma nova concepção - a de Comunicação Empresarial - impôs-se, assim, como fator imprescindível no relacionamento da Embrapa com a sociedade, em geral, e com segmentos de público, em particular, e como insumo fundamental para o fortalecimento da imagem da empresa. Mais do que isso, a política representou o marco para a orga-

2 A estrutura da Política é a seguinte: Parte I, Conceituação e Princípios Básicos; Parte II, Procedimentos de Comunicação; Parte III, Ações Estratégicas de Comunicação. O documento (versão atual) pode ser obtido em http://www.embrapa.br/publicacoes/index_htm 
nização do processo de comunicação na Embrapa, tornando-se uma espécie de "constituição" da comunicação na Embrapa. Nela não se detalhavam ações, planos, projetos e programas específicos, mas se estabeleciam orientações e normas para planejamento e execução, sistematizando a comunicação e maximizando seu desempenho.

\section{A implantação da Política}

As primeiras ações resultantes do esforço da empresa para implantar sua Política de Comunicação foram a instalação de estruturas físicas e organizacionais nos centros de pesquisa - áreas de Comunicação Empresarial (ACEs); a criação, no interior, do Sistema Embrapa de Gestão de um macroprograma para abarcar todos os projetos e atividades de comunicação conduzidos na empresa; a contratação de novos profissionais para a área e a realização de treinamentos.

Simultaneamente a essas iniciativas, as ações de comunicação da Embrapa, em parceria com outras áreas e setores da empresa, voltaram-se não apenas para o suporte ao processo de transferência de tecnologia, mas, também, e necessariamente, ao fortalecimento da marca e à busca por qualidade na Comunicação Institucional (ou Corporativa), de modo a honrar conceitos, diretrizes e valores estabelecidos pela Política.

Diversos foram, a partir de 1996, as estratégias e instrumentos utilizados para normatizar ou efetivar as disposições contidas na Política de Comunicação e para apoiar a internalização dos novos conceitos e a mudança da cultura interna.

Manuais de relacionamento com a imprensa, de atendimento ao cliente, de editoração, de eventos, de identidade visual, de redação de textos jornalísticos vieram padronizar os procedimentos de comunicação e dar unidade aos discursos e ações da empresa. Iniciativas voltadas para melhorar o atendimento aos públicos receberam reforço, com campanhas internas comportamentais, com a criação dos SACs on-line (Serviços de Atendimento ao Cidadão/Cliente) e da Ouvidoria, e com treinamentos nos serviços de recepção, atendimento telefônico, transporte e secretaria. Uma nova visão de valorização do cliente e do cidadão ganhava corpo na Embrapa.

Paralelamente, pesquisas de satisfação do cliente começaram a ser realizadas, tanto para subsidiar a avaliação de desempenho dos centros de pesquisa e das unidades da 
POLÍTICA DE COMUNICAÇÃO E GESTÃO EMPRESARIAL: A EXPERIÊNCIA DA EMBRAPA • JORGE DUARTE E HELOIZA DIAS DA SILVA

administração central quanto para nortear os processos de melhoria das atividades conduzidas pela empresa.

Como resultado direto da implantação da Política de Comunicação, a Embrapa mudou a sua marca, algo que no início parecia proposta inexequível até para a equipe de comunicação e que acabou aprovada em votação direta pelos empregados. Também foi definida uma identidade visual e foram criadas assinaturas-síntese para as suas unidades de pesquisa, em substituição às utilizadas até então. ${ }^{3}$

O impacto positivo dessa iniciativa pôde ser constatado, por exemplo, na análise do clipping do noticiário veiculado pela imprensa. O nome e a imagem da Embrapa passaram a se apresentar à sociedade de maneira corporativa. A empresa começou a ser percebida como uma única Embrapa, em lugar de dezenas de unidades de pesquisa dispersas geograficamente e desassociadas institucionalmente.

\section{A Comunicação hoje}

Com base nesses fatores e em vários outros, a área de comunicação da Embrapa foise estruturando e hoje a empresa conta com 138 profissionais atuando nas áreas de Comunicação Empresarial e de Comunicação Empresarial e Negócios Tecnológicos nas Unidades Descentralizadas de Pesquisa (UDs) e na sede, em Brasília.

A formação e a distribuição desses profissionais pode ser resumida da seguinte maneira (dados de 2007): são 91 profissionais atuando em UDs (60 jornalistas, 24 relações-públicas e sete publicitários) e os demais, na sede, sendo 29 na assessoria de Comunicação Social (20 jornalistas, oito relações-públicas e um publicitário, entre outros profissionais de diferentes habilitações).

A Política de Administração da Embrapa, orientada por seu Plano Diretor, sustentase, desde 1995, em três políticas setoriais: Política de Pesquisa e Desenvolvimento (PP\&D), Política de Transferência de Tecnologia (PTT) e Política de Comunicação Empresarial (PCE). A coordenação da PCE é de responsabilidade da Assessoria de Comunicação Social (ACS), subordinada à presidência da empresa.

3 A existência de diferentes razões sociais, nomes e siglas para identificar os centros de pesquisa criava confusão fora da organização, gerava competitividade interna entre os centros, que priorizavam suas próprias marcas e nomes. Essa pluralidade de representações não viabilizava a sinergia e dificultava a consolidação da marca Embrapa. A sociedade nem sempre conseguia perceber que os diferentes centros de pesquisa eram unidades da Embrapa. Não havia, no nome ou na sigla, qualquer elemento que identificasse a empresa. As siglas pelas quais as unidades da Embrapa eram denominadas foram substituídas por nomes que sintetizam os produtos, temas ou ecorregiões, objetos da atuação da empresa. Por exemplo: em lugar de CPAC (Centro Nacional de Pesquisa de Cerrados da Embrapa), passou-se a usar Embrapa Cerrados - simples e eficiente. 
A assessoria está estruturada em três coordenadorias que atuam nas áreas de imprensa, Relações Públicas e Publicidade, além daquela relacionada ao monitoramento da própria Política de Comunicação. Cabe ainda à ACS, como órgão responsável pela condução da PCE, coordenar todas as ações de comunicação realizadas pelas UDs da organização.

A atuação da ACS é orientada por diretrizes, valores e procedimentos gerais estabelecidos na Política de Comunicação e no Plano Diretor da empresa, bem como por dois focos básicos e complementares: institucional e mercadológico.

O primeiro tem por objetivo criar ou reforçar os relacionamentos da empresa com os diversos públicos de interesse (empregados, governo, clientes, comunidade científica, imprensa, estudantes etc.) e, com isso, legitimar suas ações junto a esses públicos e fortalecer a imagem da organização. O segundo foco - mercadológico - refere-se às ações de comunicação realizadas para apoiar o processo de transferência de tecnologias, produtos e serviços produzidos pela empresa a seus clientes e usuários. Com esse foco, são desenvolvidas tanto ações de comunicação técnica quanto promocional.

A ACS também responde pelo planejamento global das atividades de comunicação da Embrapa, gerenciando, em conjunto com o Serviço de Transferência de Tecnologias, o Macroprograma IV - Transferência de Tecnologia e Comunicação Empresarial -, um dos cinco macroprogramas no Sistema Embrapa de Gestão (SEG). Nesse macroprograma estão reunidos todos os projetos da empresa nas áreas de comunicação e de transferência de tecnologia, executados em forma de planos anuais. Esses, por sua vez, são avaliados tanto no que se refere ao cumprimento das metas propostas quanto à sua efetiva contribuição para a empresa.

Cabe ressaltar que, além de contar com os projetos e planos de comunicação de cada unidade descentralizada, a Embrapa tem também, dentro do SEG, projetos corporativos de comunicação, cujas ações envolvem toda a empresa, e planos anuais de comunicação corporativa (a cargo da ACS), nos quais constam as atividades que deverão ser realizadas de forma integrada pela sede e pelas UDs.

A prática da comunicação da Embrapa é orientada pelas seguintes diretrizes, constantes em seu IV Plano Diretor ${ }^{4}$ (EMBRAPA, 2004, p. 29-30):

- Criar, manter e ampliar fluxos, canais e espaços formais e informais de diálogo e influência recíproca entre a empresa, seus públicos estratégicos e os atores sociais organizados.

- Monitorar os ambientes interno e externo, de forma a contribuir para o pro-

4 Em seu IV PDE 2004-2007, a empresa estabelece sua missão, visão e objetivos, bem como as diretrizes estratégicas para as áreas de pesquisa; desenvolvimento e inovação; transferência de tecnologia e socialização do conhecimento; gestão de pessoas; modelo organizacional; gestão organizacional; e Comunicação Empresarial. 
cesso de definição de estratégias para as demandas político-institucionais, de Pesquisa \& Desenvolvimento e de Transferência de Tecnologia.

- Participar da construção de redes, intra e interinstitucionais, nacionais e internacionais, envolvendo os principais atores do processo da comunicação, em especial os formadores de opinião, contribuindo para o fortalecimento da imagem da Embrapa e a identificação de demandas sociais.

- Aprimorar o processo de gestão da identidade visual da Embrapa, garantindo a integridade da imagem e da marca Embrapa.

- Aprimorar a sintonia entre os focos institucional e mercadológico da Comunicação Empresarial, promovendo o fortalecimento da imagem da empresa.

Para a presente descrição, agrupamos as ações atuais de comunicação da empresa em duas categorias: comunicação interna e comunicação externa.

No âmbito interno, diversos instrumentos vêm sendo utilizados pela Embrapa para melhorar a comunicação entre empregados e entre eles e os dirigentes da empresa, tais como: edição de informativos impressos como o Folha da Embrapa e on-line como o Todos.Com; videoconferências interativas; eventos de integração (a exemplo do Festival de Arte e Cidadania, da Semana da Qualidade de Vida, de gincanas educativas e do programa Conheça a Embrapa (em que empregados participam de visitas programadas tanto na sua unidade quando nas demais unidades da empresa); carta do presidente; jornal mural etc.

No âmbito da comunicação externa, busca-se desenvolver atividades segmentadas por público, embora seja operacionalmente inviável produzir veículos de comunicação para todos os tipos de público com os quais a empresa se relaciona.

Como exemplos, podem-se citar: o boletim Em Pauta, a Carta ao Editor, o Guia de Fontes e o Banco de Notícias, destinados a jornalistas e formadores de opinião da área da imprensa; cursos de cozinha experimental, voltados, principalmente, para donas-de-casa; o Programa Embrapa \& Escola, dirigido a estudantes de ensino médio e fundamental (em 2006, 456 escolas e 63,3 mil alunos foram atendidos na sede e 826 escolas e 187.738 alunos nas unidades descentralizadas); a Vitrine de Tecnologias, em que são apresentados resultados da pesquisa agropecuária para públicos diversos, como técnicos, produtores, estudantes etc.; e a realização da feira Ciência para a Vida, destinada a atingir preferencialmente o público urbano de Brasília (60 mil visitantes em 2006).

Outras ações de comunicação direcionadas a públicos específicos, nas áreas técnica, científica e institucional, são conduzidas rotineiramente pela empresa, a exemplo de dias-de-campo para produtores e técnicos; simpósios científicos; exposições e concursos (como o Prêmio Embrapa de Reportagem).

Para os segmentos do setor rural, a empresa produz, por exemplo, desde 1998, o Dia 
de Campo na TV, transmitido para todo o país, em parceria com o Canal Rural (Net, Sky e parabólica) $)^{5}$, e o programa de rádio Prosa Rural, voltado para os jovens e produtores familiares do semi-árido, Vale do Jequitinhonha e região Norte do país. Esses dois programas são realizados pela Embrapa Informação Tecnológica, com o acompanhamento da ACS.

A ACS e as ACEs / ACNs executam também atividades de rotina, tais como:

- Área de imprensa: produção de releases e pautas para a imprensa diária e especializada; articulação de entrevistas e matérias especiais; produção de notícias para as páginas da Embrapa na Internet e intranet; edição e disponibilização de clipping eletrônico e impresso; realização de treinamentos (media training)6;

- Relações Públicas: organização de eventos protocolares e comemorativos; apoio à organização de eventos técnicos e institucionais; edição de calendário de eventos; participação em feiras e exposições; acompanhamento de visitas; e

- Publicidade e promoção: campanhas institucionais, informativas e educativas (âmbito interno e externo); veiculação de anúncios institucionais e de serviços (a Embrapa mantém contrato com agência de publicidade licitada); produção de publicações e outros materiais institucionais e promocionais.

Ainda, a empresa tem em Brasília uma unidade especializada na produção de informação: a Embrapa Informação Tecnológica que, entre outras atribuições, edita as publicações técnicas e científicas produzidas pela instituição ${ }^{7}$. Finalmente, para auxiliar a gestão das atividades de comunicação, dispõe de seis manuais sobre identidade visual, eventos, relacionamento com a imprensa, editoração, redação jornalística e atendimento ao cliente. Realiza, também, embora ainda eventualmente, pesquisas de opinião, de clima organizacional e de satisfação do cliente, e faz, mensalmente, análise qualitativa e quantitativa da presença da empresa no noticiário.

\section{Comunicação Institucional e Comunicação Mercadológica - a revisão da Política}

Em 2002, depois de sete anos da edição da Política de Comunicação, um grupo de trabalho foi criado para a revisão do documento. Políticas, em geral, devem ser atualizadas e acompanhar as mudanças internas e externas à organização. Conceitos, valores, diretrizes e procedimentos devem, portanto, adequar-se a novos cenários.

5 Esse programa, cujas perguntas são respondidas ao vivo, é aberto à participação do público por fax, e-mail ou pelo telefone (0800).

6 A Embrapa mantém, em média, 500 inserções/mês na mídia nacional.

7 A Embrapa Informação Tecnológica também produz os programas Dia de campo na TV e Prosa Rural. 
A primeira versão da Política previa que as diferentes modalidades de comunicação existentes na empresa - administrativa, científica, governamental, mercadológica, social e para transferência de tecnologia - respondessem pela execução de trabalhos específicos, sem, no entanto, perder de vista a articulação entre si. Na revisão - e essa é uma das mudanças em destaque -, as modalidades foram inseridas em dois focos principais da comunicação - o institucional, ou corporativo, e o mercadológico -, focos esses já contemplados no primeiro documento.

Para atender ao foco institucional, a comunicação passou a criar ou reforçar relacionamentos que promovam a legitimação da empresa nos diversos públicos de interesse - colaboradores, clientes, governo, comunidade científica, imprensa etc. Nesse caso, ela prioriza ações, fluxos e canais que contribuem para dar maior visibilidade à gestão administrativa e à filosofia negocial, à prática da responsabilidade social e à competência técnica e científica da Embrapa. Busca garantir à opinião pública o acesso a informações confiáveis sobre a empresa e, assim, meios para que ela acompanhe e avalie o desempenho da organização. A comunicação cumpre papel importante no gerenciamento da imagem institucional, e abarca as atividades de assessoria de imprensa, Relações Públicas, promoção, publicidade e propaganda, jornalismo empresarial e os programas de identidade visual e de comunicação interna (EMBRAPA, 2002).

A comunicação de foco mercadológico está fortemente vinculada ao apoio à transferência de tecnologia para o setor produtivo. De forma diferente do institucional, o foco mercadológico é subordinado mais diretamente às exigências do próprio mercado. A transparência continua sendo um valor essencial, mas muitas vezes o mercado exige que a informação esteja resguardada para que o conhecimento adquirido, patrimônio maior das instituições de ciência e tecnologia, seja protegido.

Em função das mudanças em alguns focos de atuação da empresa pelo atual governo, novos ajustes estão sendo efetuados neste momento na Política de Comunicação da Embrapa, notadamente no que se refere à comunicação interna, área considerada estratégica pela direção da empresa, conforme podemos observar pelo depoimento do seu diretor-presidente, Silvio Crestana 8 :

"O nosso grande desafio é melhorar a comunicação interna da empresa. Essa área é cada vez mais importante para as instituições que geram conhecimento, como a Embrapa, e que têm como maior capital os seus recursos humanos, os seus empregados. (...) É preciso entender que há dois tipos de conhecimento: o explícito, que é aquele que podemos quantificar, gerar relatórios e avaliações formais, e o conhecimento tácito, que é aquele que es- 
tá na cabeça, no coração e nas emoções das pessoas, e que foram adquiridos ao longo de suas experiências profissionais e pessoais. A estratégia fundamental para o êxito de qualquer instituição, mas em especial para as que desenvolvem CひT e inovação, é mobilizar e estimular os seus empregados a contribuir não apenas com o conhecimento explícito, mas, e principalmente, com o conhecimento tácito. E isso não se faz sem comunicação."

\section{Considerações finais}

Embora aqui apresentados de forma sumária, os resultados deste trabalho permitemnos observar o quanto a Embrapa evoluiu nos últimos dez anos na gestão da comunicação a partir da implantação, em 1996, de sua Política de Comunicação. Princípios, diretrizes e valores têm orientado as atividades dessa área e geraram, desde então, uma série de conseqüências práticas determinantes para a qualificação da comunicação, como a criação de uma "cultura de comunicação" na empresa, a valorização do público interno e do público urbano nas estratégias de comunicação, o engajamento de pesquisadores e dirigentes no tema, a capacitação de profissionais (inclusive via mestrado e doutorado), a incorporação de comunicação aos planejamentos gerais das unidades e da própria Embrapa, a criação de redes internas de discussão sobre comunicação e, por fim, a conscientização de todos de que a boa comunicação é tarefa de cada um.

Hoje, como resultado dessa Política, a Embrapa tem planos de comunicação formalmente inseridos em seu Sistema de Gestão, utiliza mecanismos de acompanhamento e de avaliação de resultados e trabalha, mesmo que ainda abaixo de seu potencial, com programas de comunicação segmentados por público.

Entre os impactos também estão a maior presença da Embrapa na mídia, uma maior interação com os públicos de interesse, o fortalecimento da imagem institucional e da marca, a conscientização interna sobre a importância da comunicação, a integração entre áreas e unidades, uma maior participação interna, uma unicidade de discurso e uma maior aproximação com a sociedade.

Embora a Embrapa tenha obtido significativos avanços na área de comunicação nos últimos dez anos, a dimensão da estrutura da Embrapa e a abrangência e complexidade de suas ações estão a criar desafios e a exigir da empresa - permanentemente novas soluções de comunicação.

Os resultados obtidos pela empresa nessa área, e apresentados de forma sumária neste trabalho, evidenciam o quanto é importante para uma organização - seja privada ou pública - ter uma cultura de comunicação sintonizada com o seu processo de gestão. A experiência da Embrapa na construção e implementação de sua Política de Comunicação pode tornar-se ponto de partida para outros órgãos e entidades públicas que desejem investir nessa área. 
POLÍTICA DE COMUNICAÇÃO E GESTÃO EMPRESARIAL: A EXPERIÊNCIA DA EMBRAPA • JORGE DUARTE E HELOIZA DIAS DA SILVA

\section{Referências}

BUENO, Wilson da Costa. Comunicação na era da qualidade. São Paulo: Comtexto/Unimed Amparo, 1995.

Por que uma política de comunicação. In: Desenvolvimento da comunicação nas organizações estaduais de pesquisa agropecuária-OEPAS. Brasília: Embrapa/Comtexto, 2001.

. Comunicação empresarial: teoria e pesquisa. Barueri, SP: Manole, 2002.

. A auditoria de imagem como estratégia de inteligência empresarial. Disponível em: <http://www.comtexto.com.br/telacomempreartigowilauditoria.htm>. Acesso em: fev. 2004.

Cultura empresarial. Disponível em: <http://www.comunicacaoempresarial.com.br/conceitoculturaempresarial.htm>. Acesso em: out. 2003.

CORRADO, Frank M. A força da comunicação. São Paulo: Makron Books, 1994.

DUARTE, Jorge. A atuação do jornalista na comunicação empresarial: o caso Embrapa. Dissertação de mestrado. São Bernardo do Campo, SP: Umesp, 1996.

Jornalistas na Embrapa. In: DUARTE, Jorge e RIBEIRO, Rosa Maria. (orgs.). Comunicação em ciência e tecnologia: estudos da Embrapa. Brasília, DF: Embrapa Informação Tecnológica, 2006, p. 225-256.

DUARTE, Márcia Yukiko Matsuuchi. Estudo de Caso. In: BARROS, Antonio (org). Métodos e técnicas de pesquisa em comunicação. São Paulo: Atlas, 2005.

EMBRAPA-Comtexto. Política de comunicação empresarial. Brasília, Embrapa/Comtexto, 1995; 2002.

EMBRAPA. Relatório de atividades ACS - 1995 - 2002. Brasília, ACS, 2003.

. III Plano Diretor da Embrapa: Realinhamento estratégico 1999-2003. Secretaria de Administração Estratégica. Brasília: Embrapa, 1998.

. IV Plano Diretor da Embrapa - 2004 - 2007. Brasilia: Embrapa/Secretaria de Administração Estratégica. Brasília, 2004.

GARRIDO, Francisco Javier. Comunicación estratégica. Barcelona: Ediciones Gestión 2000, 2001.

KUNSCH, Margarida. Planejamento de relações públicas na comunicação integrada. São Paulo: Summus, 2003. . Relações públicas e modernidade. Novos paradigmas na comunicação organizacional. São Paulo, Summus Editorial, 1997.

PUTNAM, Linda L.; COSTA, Joan; e GARRIDO, Francisco Javier. Comunicación empresarial. Barcelona: Gestión 2000, 2002. 